\title{
EDUCAÇÃO FÍSICA NA EDUCAÇÃO INFANTIL E PEDAGOGIA DE PROJETOS: BATENDO ASAS JUNTOS NA ESCOLA
}

\author{
Tiago Wagner ${ }^{1}$ \\ Derli Juliano Neuenfeldt ${ }^{2}$
}

\begin{abstract}
Resumo: $\mathrm{O}$ objetivo deste estudo foi propor e analisar possibilidades de articular, no contexto da Educação Infantil, a Educação Física com a proposta pedagógica de uma escola, a partir da Pedagogia de Projetos. A pesquisa foi realizada em uma escola do Vale do Rio Pardo/RS/BRA, a partir da abordagem qualitativa. Participaram do estudo a diretora, a supervisora e a professora da pré-escola. Foram realizadas entrevistas semiestruturadas, observação sobre a rotina da única turma da préescola do educandário e análise do Projeto Político Pedagógico, com a finalidade de compreender mais sobre a organizaçáo do contexto com relação a Educação Infantil e a Educaçáo Física. Quanto à análise das informaçôes, duas categorias emergiram: a) Educação Infantil e Educação Física no contexto investigado e b) escola e família contribuindo para um projeto de jogos e brincadeiras tradicionais na Educação Infantil. Com base nas categorias, foram pensadas práticas docentes em um projeto com o tema jogos e brincadeiras tradicionais, que envolveriam as famílias, a cultura das crianças e aprendizagens que transcendessem os muros da escola. Teve-se como resultado, propostas de açóes para o projeto, como a confecção de brinquedos com materiais recicláveis, a criação de jogos pintados no espaço da escola e a vivência de brincadeiras e jogos tradicionais.
\end{abstract}

Palavras-chave: Educação Infantil. Educação Física. Pedagogia de Projetos. Ensino.

\section{PHYSICAL EDUCATION IN PRESCHOOL EDUCATION AND PROJECT PEDAGOGY: WING FLAPPING TOGETHER AT SCHOOL}

Abstract: The objective this study was to propose and analyze possibilities of articulation in the
context of Preschool, between Physical Education and the pedagogical proposal of a school, from
the Project Pedagogy. The research was performed in a school of Vale do Rio Pardo/RS/BRA, from
the qualitative approach. In this research participated the director, the supervisor and the teacher of

1 Universidade do Vale do Taquari - Univates/Brasil. Graduando em Educaçáo Física - Licenciatura. tiago.wagner@universo.univates.br

2 Universidade do Vale do Taquari - Univates/Brasil. Doutor em Ciências: Ambiente e Desenvolvimento. Professor do Curso de Educação Física - Licenciatura da Univates/Brasil. derlijul@univates.br 
preschool class. Were performed semi-structured interviews, observation about the class of Preschool routine and analysis of Pedagogical Political Project to understand about the context organization concerning the Preschool and the Physical Education. When analyzing information, emerged two categories: a) Preschool and Physical Education in context investigated and b) school and family contributing for a games and plays traditional project in Preschool. Based on categories, docent practices were thought on a project with the theme traditional games and plays that involve the families, the children's culture and learnings that transcend the school's walls. As a result, were created action proposes to the project like of toy confection with recyclable materials, the creation of painted games in school yard and the experience with traditional games and plays.

Keywords: Preschool Education. Physical Education. Project Pedagogy. Teaching.

\section{PENSANDO EM VOAR}

A Educação Infantil é a primeira etapa da Educação Básica. Ela abrange os processos de ensino que ocorrem com crianças de 0 a 3 anos, de forma não obrigatória; e de 4 a 5 anos, de forma obrigatória na pré-escola. Para compreender mais sobre a Educação Infantil, é preciso, antes de tudo, conhecer os sujeitos dessa etapa da educação: as crianças.

Moura, Viana e Loyola (2013) afirmam que a criança se adapta às questóes históricas, sociais e culturais de cada época. De acordo com os autores, é somente nos anos 60 que, no Brasil, a infância começa a ser assistida pelo Estado. O termo recebe uma concepção que identifica a criança como sujeito de direitos que necessita de cuidados especiais.

Atualmente, a criança é considerada um ser histórico-social, condicionada a fatores culturais e sociais, e, portanto, dinâmico. "A criança é considerada um ser competente, tem suas necessidades, seu modo de pensar e agir, modos que lhe são próprios" (NIEHUES; COSTA, 2012, p. 287). Contudo, as representaçōes de infância mudam conforme o contexto em que ela vive. Neste sentido, Ariès (2012) destaca que a infância não será vivenciada da mesma maneira por todos devido a questóes econômicas, sociais e culturais.

A escola se configura como um espaço democrático, onde a infância é vivida. Quinteiro (2011) afirma que é preciso mais do que garantir o acesso à educação dos pequenos. Para a autora, é importante a escola ser um local agradável, que a criança frequenta não só por obrigação, mas também por entender que ali está vivenciando o seu próprio processo de formaçáo. Evidenciam-se no dia a dia da escola aspectos que visam à formação do indivíduo, de forma a prepará-lo de maneira mais efetiva possível para a próxima etapa de educação que está por vir. Contudo, exatamente onde a criança teria o maior tempo de "ser criança" e de desfrutar a infância, essa condição, muitas vezes, é negada.

Esse tratamento da criança como um "vir a ser" se faz presente também no ambiente familiar. O tempo de ser e desfrutar a infância é acelerado na pressão da vida cotidiana, objetivando o vislumbre do sucesso no futuro. É assim que muitos pais agem no dia a dia com seus filhos. Aceleram etapas da infância e desejam que eles tenham habilidades de adultos o quanto antes, para serem bem-sucedidos na 
vida profissional que escolherem, ou que serão forçados a seguir. Dessa maneira, "este agir do adulto pode estar roubando o que é mais valioso para a criança, que é justamente o seu tempo de ser criança” (STAVISKI; SURDI; KUNZ, 2013, p. 114).

Com relação a isso, entende-se que é preciso um agir mais responsável do adulto. Destaca-se a importância da oferta de inúmeras oportunidades de escolha de conhecimentos e experiências com os quais as crianças desejam trabalhar. Para a Horn (2017), a centralidade do processo pedagógico está nas crianças, fazendo com que elas, juntamente com o professor, produzam e compartilhem suas aprendizagens.

Frente a isso, a Educação Infantil possui extrema importância para o desenvolvimento inicial do ser humano, na medida em que a infância é uma fase em que o ser humano se desenvolve por meio de novas descobertas e novas interaçóes. E é a partir desses processos presentes na educação que, segundo Freire (1996), o ser humano será capaz de intervir no mundo que o cerca. Portanto, a escola é um espaço que deve permitir à criança ser criança e desfrutar sua infância. Para isso, o professor precisa reconhecer o "ser criança" para, assim, exercer seu papel e oferecer espaços e oportunidades pedagógicas a partir da ludicidade, da brincadeira, da criação, da recriação e da imaginação, que contribuam para o desenvolvimento do ser humano na escola e para a vida.

Algo muito importante no desenvolvimento da criança com certeza é sua capacidade de brincar e se movimentar. De acordo com Surdi, Melo e Kunz (2016, p. 460), especialmente nessas atitudes os pequenos são capazes de se expressarem de uma maneira muito subjetiva: "assim, toda criança é um artista por natureza". Para Hildebrandt-Stramann (2003), o movimentar-se deve fazer parte integral da formação das crianças. $\mathrm{O}$ autor cita que essa ação sempre está relacionada a intençôes. Por exemplo: ao ver uma cadeira, cada pessoa fará um movimento diferente, mas regado de significados.

Entendendo a importância e o significado por trás de uma simples brincadeira ou movimento, no contexto da Educaçáo Infantil, a Educação Física cada vez mais vem sendo reconhecida quanto ao seu papel nessa importante etapa da educação. Muitos dos objetivos propostos e estabelecidos na Base Nacional Comum Curricular, popularmente conhecida como BNCC (BRASIL, 2018), estão diretamente relacionados com a área de estudos da Educação Física. Um exemplo disso é o objetivo "Criar com o corpo formas diversificadas de expressão de sentimentos, sensaçóes e emoçôes, tanto nas situaçóes do cotidiano quanto em brincadeiras, dança, teatro, música” (BRASIL, 2018, p. 47), o qual, entre outros, aponta para a necessidade da presença da Educação Física, enquanto componente curricular, desde a infância.

Apesar disso, Oliveira (2005) menciona que a Educação Física também tem tratado a criança como um "vir a ser", no sentindo de prepará-la para algo. A autora destaca que se precisa de um debate mais crítico sobre a infância nos cursos de formação profissional em Educação Física, a fim de pensar a criança como um "ser" no presente, e não somente no futuro. 
Com relação à formação em Educação Física, Pochmann e Neuenfeldt (2015) apontam que a Educação Infantil é a etapa de ensino pela qual os acadêmicos menos mostram interesse de atuar. Em seu estudo, constataram que os acadêmicos não se sentem preparados para atuar nesta etapa, identificando como necessários, durante sua formação, mais componentes curriculares que contemplem conhecimentos sobre a prática pedagógica na Educação Infantil.

No cotidiano das instituições de Educação Infantil, observa-se a aula de Educação Física muitas vezes desvinculada de uma intenção pedagógica que efetive as propostas de ensino nessa etapa da Educação Básica. Isso se dá porque, historicamente, a Educação Física pouco se preocupou com o campo de atuaçáo da Educação Infantil, haja vista o grande vínculo histórico da Educação Física com o meio esportivo, no qual as crianças pouco conseguem ser inseridas (AYOUB, 2001).

Porém, a Educação Física, mais recentemente, tem estudado e apresentado metodologias de ensino voltadas para crianças. Entende-se que, para a oferta de uma Educação Física significativa para as crianças, é preciso conhecer concepçóes de ensino que contemplam uma visão mais aberta dos processos educativos, permitindo que a criança possa ter participação a partir da demonstração de interesses, ideias e sugestôes que serão consideradas pelo docente na organizaçáo de sua prática pedagógica. Essas concepçóes objetivam uma formação crítica por parte das crianças. Pensa-se, então, em uma Educação Física com enfoque na formação integral dos sujeitos, oferecendo um componente curricular com conteúdos que façam sentido ao contexto em que as crianças estão inseridas e sejam, portanto, de fundamental importância para eles (FREIRE, 1994).

Nesse sentido, as abordagens de ensino Concepçóes Abertas (HILDEBRANDT-STRAMANN; LAGING, 2011), Crítico-Emancipatória (KUNZ, 1991) e Construtivista (FREIRE, 1994) abrem espaço para uma prática pedagógica direcionada e orientada a partir dos interesses das crianças, com conhecimentos que sejam significativos a elas e ao contexto em que vivem. É a partir do surgimento dessas abordagens na Educação Física no Brasil que esse componente curricular começa a ser articulado com a Educação Infantil. Elas apresentam novas formas de desenvolver as aulas, rompendo com o direcionamento técnico-esportivo, sugerindo caminhos metodológicos que articulem conhecimentos com o mundo de vida da criança. Outra abordagem interessante é a Cultural, na qual Neira (2018) define as práticas corporais como artefatos da cultura. O autor defende um currículo que promova o encontro dessas práticas, disseminando sentidos, análises, interpretações, questionamentos e diálogos entre e a partir das culturas abordadas.

$\mathrm{Na}$ Educação Infantil, entende-se que a Educação Física tem o papel de proporcionar uma diversidade de experiências. Nessas, o objetivo é que as crianças sejam capazes de criar, descobrir, inventar e reformular conhecimentos a partir de seus movimentos e ações, contribuindo para o desenvolvimento e a formação de sujeitos emancipados. Além disso, para Basei (2008), o espaço da Educação Física para as crianças deve possibilitar que, 
[...] através de situaçôes de experiências - com o corpo, com materiais e de interação social - as crianças descubram os próprios limites, enfrentem desafios, conheçam e valorizem o próprio corpo, relacionem-se com outras pessoas, percebam a origem do movimento, expressem sentimentos, utilizando a linguagem corporal, localizem-se no espaço, entre outras situaçóes voltadas ao desenvolvimento de suas capacidades intelectuais e afetivas, numa atuação consciente e crítica (BASEI, 2008, p. 01).

A partir dessas perspectivas, a Pedagogia de Projetos (HERNANDEZ; VENTURA, 1998) apresenta-se como um potencial caminho para concretizar os objetivos da Educaçáo Infantil. Ela vai ao encontro das novas concepçóes de ensino da Educação Física, em que a criança é a protagonista. Desse modo, podem "bater asas" conjuntamente, contribuindo para a construçáo de conhecimentos a partir de práticas vivenciadas. $\mathrm{O}$ ensino por projetos considera o contexto da criança, partindo de sua realidade e a articulando com outros saberes, na medida em que adota um tema a partir das experiências anteriores dos educandos. Professor e crianças trabalham de forma conjunta para a construção do conhecimento, e a cooperação é um elemento bastante presente nessa metodologia (SANTOS; ROYER; DEMIZU, 2017).

Ainda, a abordagem de um projeto em sala de aula permite o estudo de um tema que perpassa diversas áreas do conhecimento, tornando a interdisciplinaridade fundamental para o desenvolvimento dessa metodologia. A Pedagogia de Projetos destaca muito o fator experiência nas aulas, haja vista que, a partir das vivências, vão se assumindo novos conhecimentos que partem das experimentaçóes feitas pelas crianças. Dessa maneira, o ensinar não objetiva apenas a resposta correta, mas, sim, as experiências, os problemas e as ações para a transformação.

Na Educação Física, Hildebrandt-Stramann (2009, p. 27) defende a categoria "experiência" nas aulas, entendendo que as vivências das crianças, principalmente na rua, em contato com outras pessoas, mostram "um alto grau de autenticidade, pois as crianças e jovens procuram ali, autonomamente, seus motivos de movimento". Sendo assim, é importante considerar as experiências das crianças na escola, valorizando seus interesses. O docente deixa de impor intençóes e, assim, as experiências vivenciadas são experimentadas e entendidas subjetivamente.

A partir do lema de uma escola - "A educação nos dá asas, o conhecimento o voo para a vida" -, neste trabalho entende-se a escola, a família, os componentes curriculares e as abordagens de ensino como "asas", evidenciando a importância de trabalharem em sintonia para que o "voo" ocorra e possibilite à criança acesso ao mundo do conhecimento. $\mathrm{O}$ objetivo deste estudo é propor e analisar possibilidades de articulação da Educação Física com a proposta pedagógica de uma escola, a partir da Pedagogia de Projetos, no contexto da Educação Infantil.

Espera-se que este trabalho contribua para destacar a importância de intenções pedagógicas da Educação Física na Educação Infantil que colaboram para a formação integral das crianças, a partir da abordagem de conhecimentos relacionados aos seus contextos. Dessa forma, é interessante pensar em uma articulação da Educação Física 
com relação às propostas pedagógicas do educandário, dialogando e promovendo saberes que façam sentido para a formação e atuação do educando em sociedade.

\section{PLANEJANDO O VOO}

\section{Características da pesquisa}

Esta pesquisa teve abordagem qualitativa, na medida em que investigou a subjetivação existente no contexto de estudo. De acordo com Negrine (2010, p 62), "[...] a pesquisa qualitativa tem como pressuposto científico manipular informaçóes recolhidas, descrevendo e analisando-as, para num segundo momento interpretar e discutir à luz da teoria”.

Quanto à sustentação teórica, ela foi realizada com o objetivo de levantar informaçóes com base em ideias de autores publicadas em meios escritos ou eletrônicos, como livros e artigos, a fim de construir conhecimentos prévios sobre o problema do qual a pesquisa trata. Sobre isso, para Fonseca (2002, p. 32), "o pesquisador tem de ter o cuidado de selecionar e analisar cuidadosamente os documentos a pesquisar de modo a evitar comprometer a qualidade da pesquisa com erros resultantes de dados coletados ou processados de forma equívoca".

\section{Contexto e sujeitos do estudo}

Para cumprir com os objetivos deste estudo, foi preciso entrar em um contexto no qual a Educação Infantil se faz presente. Assim, optou-se por uma Escola Municipal de Ensino Fundamental (EMEF) de um município do Vale do Rio Pardo/RS/BRA. Cabe destacar que, mesmo se denominando como escola de Ensino Fundamental, esse educandário possui uma turma de pré-escola, constituída por 20 crianças com 4 e 5 anos de idade. No que tange às aulas de Educação Física, no educandário não há professor dessa área para a Educação Infantil. Assim, a realização de atividades relacionadas à Educação Física é exercida pela professora titular da turma.

A cada ano letivo, a escola define uma frase como lema do educandário. No ano letivo de 2020, a frase "A educação nos dá asas, o conhecimento o voo para a vida" está estampada em uma parede da escola, objetivando motivar professores e estudantes para um trabalho conjunto ao longo do ano, visando à construção de conhecimentos que perpassem os muros da escola.

A escolha por esse contexto de investigação foi motivada tendo em vista que o pesquisador possui uma estreita relação com o educandário, haja vista que já foi aluno e funcionário, além de ter realizado estágio curricular obrigatório nele. Durante a atuação na instituição, foi possível perceber que ela está preocupada com a temática da diversidade cultural e do meio ambiente. Assim, algumas açóes que evidenciam esses temas são realizadas ao longo do ano, mobilizando estudantes em pesquisas, trabalhos e atividades relacionadas a uma gincana escolar. 
Ao apresentar a proposta da pesquisa para a Secretaria de Educaçáo e para a equipe diretiva, ambas prontamente entenderam como viável a realizaçáo desta investigação. Contudo, com relação aos sujeitos da pesquisa, Minayo (2002) entende que a aproximação com eles deve ser feita de forma gradual, respeitosa e compreendendo as manifestações existentes na comunidade pesquisada. Dessa forma, neste trabalho, buscou-se primeiramente entender o funcionamento do contexto escolar, para posteriormente realizar abordagens diretamente com os sujeitos investigados.

Para o estudo, teve-se como sujeitos pessoas que têm relação direta dentro da escola, quanto às situaçóes de aprendizagem e práticas pedagógicas desenvolvidas na Educação Infantil. Assim, participaram da pesquisa a professora da turma da préescola, a diretora e a supervisora do educandário.

\section{Instrumentos e procedimentos de coleta de informaçóes}

Quanto aos instrumentos de coleta de informaçóes, foram utilizadas observaçóes e entrevistas para investigar o contexto foco da pesquisa e um diário de campo para organizar e registrar informaçóes extraídas a partir do contexto e grupo pesquisado. Também foi solicitado à direçáo do educandário acesso ao Projeto Político Pedagógico da escola, a fim de identificar a filosofia e ideias da instituição com relação aos processos de ensino e aprendizagem. Foram realizadas cinco idas ao educandário investigado, sendo uma de aproximação ao contexto para apresentação da pesquisa e sobre o que se investigaria, três destinadas às entrevistas e uma para a realização da observaçáo. Essas atividades foram realizadas entre os dias 27 de fevereiro e 17 de março de 2020.

Com relação às entrevistas, foram semiestruturadas, visando a garantir informaçôes diretamente relacionadas com as temáticas da pesquisa, mas também dando liberdade ao entrevistado de expor opiniōes e informaçôes que julgasse serem importantes (NEGRINE, 2010). Foram realizadas entrevistas com a professora da turma da pré-escola, com a supervisora e com a diretora do educandário, tendo como foco temático principal suas percepçôes sobre a Educação Infantil e o espaço da Educação Física nesta etapa da Educação Básica. Além disso, as entrevistadas relataram um pouco de suas experiências de prática docente com projetos. $\mathrm{O}$ registro das entrevistas foi feito por gravaçáo de voz com consentimento dos entrevistados, respeitando o anonimato dos participantes. Após a realizaçáo das entrevistas, a gravação foi transcrita, prezando totalmente pela fidedignidade ao que foi dito, sem resumos ou interpretações subjetivas. Depois de ser transcrita, foi devolvida aos entrevistados para eles lerem e autorizarem o seu uso.

Quanto à observação, foi feita a partir do cotidiano da turma investigada, em relação à organização da escola em geral e também com relação ao funcionamento do recreio na instituição. Foi possível relacionar os registros da observação com o Projeto Político Pedagógico, documento que mostra a identidade do educandário e é utilizado como instrumento metodológico (PROJETO POLÍTICO PEDAGÓGICO, 2019). 


\section{Análise das informaçóes}

A análise de informaçôes recolhidas foi feita a partir de categorias de análise. Essas categorias foram definidas de acordo com o interesse do pesquisador em fenômenos cuja dimensão esteve mais relacionada ao tema de investigação. Nesta pesquisa trabalhou-se com "categorias emergentes" (MORAES, 2007, p. 92), que se manifestaram no decorrer da investigação.

A partir da análise das informaçóes, foram identificadas unidades de análise que se relacionam à diversidade cultural; ao trabalho de conhecimentos que perpassam o ambiente da sala de aula e relacionam-se com a vida da criança; à prática constante de brincadeiras e jogos por parte das crianças no ambiente da escola; e à importância do espaço de fala e opiniáo do educando nas aulas. Delas, duas categorias emergiram a partir de características identificadas no contexto: a) Educação Infantil e Educaçáo Física no contexto investigado e b) escola e família contribuindo para um projeto de jogos e brincadeiras tradicionais na Educação Infantil.

Após categorizar essas informaçôes, foi preciso interpretá-las e analisálas, produzindo argumentos e mostrando novas compreensóes a partir dos dados investigados. Nessa etapa, "o desafio do pesquisador é superar meras descrições e ampliar, reconstruir teorias, a partir das já existentes e que dão suporte ao estudo" (NEUENFELDT, 2016, p. 102).

\section{Cuidados éticos}

Em relação aos cuidados éticos da pesquisa, é importante destacar que os participantes assinaram o Termo de Consentimento Livre e Esclarecido (TCLE). Nesse documento, é assegurada ao participante a confidencialidade das informaçóes por ele prestadas, podendo também exigir os resultados de suas participaçóes na pesquisa. Além disso, o pesquisador deve esclarecer dúvidas e questionamentos do pesquisado quando este solicitar. $\mathrm{O}$ projeto da presente pesquisa foi aprovado pelo Comitê de Etica em Pesquisa da Univates ${ }^{3}$. Visando a manter o sigilo dos sujeitos da pesquisa, quando eles forem citados, não serão utilizados seus nomes, e, sim, os respectivos cargos que ocupam na instituição.

\section{DESCOBRINDO A CAPACIDADE DE VOAR: Educaçáo Infantil e Educaçáo Física no contexto investigado}

Ao analisar o Projeto Político Pedagógico, sobre os processos de ensino para todos os níveis, o documento sugere que a produção e a construção do conhecimento em sala de aula devem ser significativas às crianças e que os docentes sejam capazes de compreender as necessidades do educando e a realidade da comunidade em

3 Projeto aprovado no Comitê de Ética em Pesquisa da Univates. Parecer n.o 3.580.090 de 19/09/2019. 
que vivem, para, assim, partirem para a prática pedagógica. Em virtude disso, com relação ao planejamento didático, o Projeto Político Pedagógico pontua que deve ser flexível e se adequar aos momentos e situaçóes a serem vividos. O documento destaca também o trabalho docente a partir de metodologias ativas e projetos interdisciplinares (PROJETO POLÍTICO PEDAGÓGICO, 2019).

Essas orientaçóes presentes no documento relacionam-se com as metodologias emergentes no ensino da Educação Física (OLIVEIRA, 1997), na medida em que a criança, como sujeito central nas aulas, é um aspecto muito importante nelas. De acordo com Oliveira (1997, p. 26), nas metodologias emergentes da Educaçáo Física, o objetivo central é muito similar entre elas: "oferecer uma disciplina de Educação Física recheada de conteúdos significativos e de fundamental importância aos participantes".

Outro ponto-chave para se pensar a Educação Física na atualidade é o enfoque para o desenvolvimento e a formação integral dos sujeitos, na medida em que o componente curricular oportunize situaçóes que instigam um agir autônomo da criança (KUNZ, 1991). E é indo ao encontro disso que a escola define que a formação de seus estudantes seja pautada também no desenvolvimento de sujeitos capazes de "[...] pensar por si, compreender, interpretar e interagir no meio social em que vivem [...]" (PROJETO POLÍTICO PEDAGÓGICO, 2019, p. 12), e não somente na transmissão de conhecimentos específicos das áreas curriculares.

O Projeto Político Pedagógico da escola utiliza a BNCC (BRASIL, 2018) como documento orientador na definição dos conhecimentos essenciais que seus estudantes têm o direito de aprender. Dessa forma, a escola entende que pode "ensinar além da Base, mas não menos do que ela determina" (PROJETO POLÍTICO PEDAGÓGICO, 2019, p. 14). É importante destacar que a BNCC (BRASIL, 2018) é uma referência obrigatória na formulação dos Projetos Políticos Pedagógicos de todas as escolas. Contudo, é necessário salientar que esse documento não representa o currículo, e, sim, os objetivos de aprendizagem deste (PROJETO POLÍTICO PEDAGÓGICO, 2019).

Para a Educação Infantil, etapa da educação investigada neste trabalho, a BNCC (BRASIL, 2018) assegura o direito de a criança aprender e se desenvolver convivendo, brincando, participando, explorando, expressando e se conhecendo. De acordo com a Base, as instituições de Educação Infantil têm o objetivo de "ampliar o universo de experiências, conhecimentos e habilidades" (BRASIL, 2018, p. 36) das crianças, articulando a suas propostas de ensino os conhecimentos construídos na vida fora da escola, em família e comunidade e também construindo conhecimentos que sejam úteis para além dos muros da escola. Essa ideia trazida na BNCC (BRASIL, 2018) vai ao encontro do que o Projeto Político Pedagógico da escola traz em relaçáo aos seus anseios para a sociedade. De acordo com o documento, a escola deseja a formação de um cidadão que

[...] seja consciente e crítico da sua atuação no meio em que vive. Que consiga resolver situaçóes diversas, através do diálogo, sendo um ser humano mais fraterno e comprometido, para uma convivência mais harmônica e 
sustentável num âmbito social, cultural e ambiental (PROJETO POLÍTICO PEDAGÓGICO, 2019, p. 11).

Um aspecto bem marcante na escola, segundo a diretora do educandário, é a presença constante, durante o ano letivo, do trabalho com temas transversais (Entrevista, 05/03/2020). O Projeto Político Pedagógico (2019, p. 19) da escola estabelece que a abordagem desses temas deve ser voltada para "a compreensão e para a construção da realidade social e dos direitos e responsabilidades relacionados com a vida pessoal e coletiva”. O tema cultura é um dos exemplos trazidos no Projeto Político Pedagógico. "É papel da escola abordar a diversidade cultural, sendo ela de gênero, raça, etnia, religiáo ou língua, frisando sempre o respeito às diferenças e o espírito de coletividade" (PROJETO POLÍTICO PEDAGÓGICO, 2019, p. 20).

Outro aspecto interessante para destacar é que "os alunos da escola são provenientes de várias localidades, o que diversifica bastante a cultura e os costumes dentro desta instituição" (PROJETO POLÍTICO PEDAGÓGICO, 2019, p. 28). Entendendo isso, é preciso dar abertura para que a diversidade da comunidade escolar seja reconhecida, abordando uma gama diversa de temas e conhecimentos que estejam de alguma forma vinculados à realidade de todos as crianças.

Segundo o Projeto Político Pedagógico (2019), com relação às famílias dos estudantes, deve ser trabalhado um contato harmonioso entre escola e família, zelando pela integração da sociedade com a escola. Para a diretora (Entrevista, 05/03/2020), fazendo uma analogia entre estudante e pássaro, "[...] um passarinho não consegue voar com uma asa só [...]". Isso evidencia a importância de escola e família serem aliadas nos processos educativos de suas crianças. Esse fato, segundo a diretora, é efetivado no educandário. Reitera-se que a relação entre a educação e o voar está expressa também pela seguinte frase pintada em uma parede da escola: "A educação nos dá asas, o conhecimento o voo para a vida”.

Em relaçáo à turma, durante a entrevista com a professora titular, quando questionada sobre os objetivos de suas aulas, ela explicou que inicialmente trabalha com conteúdos que possuem uma aplicação não somente na escola, como também na vida da criança. A docente enfatiza que é importante para o professor "[...] saber que existe uma intencionalidade no ensino e pensar o motivo do professor estar trabalhando tal conteúdo" (Entrevista, 17/03/2020).

Com relação à docência na Educação Infantil, a professora cita que "o planejamento é essencial" (entrevista, 17/03/2020). Além disso, ela afirma ser muito importante também refletir sobre as ações realizadas, para, então, novamente pensar/ planejar outras, evidenciando que o acontecimento desse processo da docência deva ser feito com base no ciclo planejamento-ação-reflexão. Em concordância com isso, Ostetto (2000, p. 177) expõe que

[...] planejar é essa atitude de traçar, projetar, programar, elaborar um roteiro para empreender uma viagem de conhecimento, de interação, de experiências múltiplas e significativas para/com o grupo de crianças. Planejamento pedagógico é atitude crítica do educador diante de seu trabalho docente. Por 
isso não é uma fôrma! Ao contrário, é flexível e, como tal, permite ao educador repensar, revisando, buscando novos significados para sua prática docente.

Com relação à reflexão sobre a prática realizada, Perrenoud (1999) afirma que jamais será inteiramente solitária, indicando a importância da troca de experiências entre os docentes. $\mathrm{O}$ autor sugere que a reflexão aconteça durante a ação, de forma a regular algum processo que esteja desorientado, e também posteriormente à ação, permitindo assim uma análise mais tranquila sobre os acontecimentos.

Durante a observação realizada na turma, percebeu-se a utilização de uma fala suave e calma da professora. As crianças se mostraram muito participativas e interativas, e a docente dá oportunidade para que elas também desenvolvam sua oralidade. "Os alunos conversam bastante, mas respeitam o momento de fala da professora" (Diário de campo, 03/03/2020). Uma das formas para chamar a atenção das crianças por parte da professora é a utilização constante de questionamentos. Os educandos são muito instigados a falarem e exporem suas ideias em sala de aula. Relacionado a isso, no ensino da Educação Física, a abordagem de Concepçóes Abertas (HILDEBRANDT-STRAMANN; LAGIN, 2011) trabalha diretamente com a solução de problemas, admitindo diversos caminhos para a solução e não se limitando somente ao trajeto traçado pelo professor.

Outro elemento muito presente na sala de aula pesquisada foi a constante utilizaçáo de materiais concretos pela professora. Um exemplo disso foi a utilização de feijão, arroz e um prato durante a aula. A professora estava ensinando os números por meio da música "1, 2, feijão com arroz; 3, 4, feijão no prato [...]" e utilizou os materiais que eram cantados para mostrar para as crianças. Assim, pode-se destacar que a utilização do material concreto, além de contribuir para tornar as aulas mais dinâmicas, estreita a relação entre conhecimento e cotidiano das crianças (FREIRE, 1996).

Com relação a práticas exercidas pelas crianças, observou-se a realização de um jogo de forma frequente quando elas estáo em tempo livre. Quando cheguei à escola para realizar a observação, fui direcionado ao ginásio, onde os estudantes de todas as turmas formam filas e os professores vão buscá-los no horário da aula. Nesse momento em que estão em fila, percebi, especialmente na turma da préescola, a realizaçáo do jogo "pedra, papel ou tesoura" por parte de algumas crianças. Em posterior conversa com a docente da turma, ela afirmou que esse jogo está muito presente no grupo, sendo a questão dos jogos e brincadeiras uma temática potencial para abordagem nas aulas.

Sobre a proposta pedagógica da Educação Física na Educação Infantil, a diretora (entrevista, 05/03/2020) diz que "precisa trabalhar muito com a coordenação, a psicomotricidade, motricidade mais fina [...], pois vejo que ali é o ápice do desenvolvimento dela [da criança], e depois terá os frutos desse trabalho". Sobre os objetivos da Educação Física na Educação Infantil, a supervisora comenta que vê a EF como aliada aos demais componentes curriculares. "Por exemplo a questão de concentração, a questão de regras, eu vejo que ela [Educação Física] trabalha muito forte isso. Eu penso que é a disciplina que vai fazer eles [estudantes] 
terem uma vida mais saudável [...], eu vejo que o corpo saudável produz mais em todas as disciplinas" (Supervisora, entrevista, 02/03/2020).

De acordo com a professora da turma, com relação ao tempo da Educação Física dentro da carga horária semanal das aulas, ela entende que pelo menos deveriam ser disponibilizados 30 minutos por dia para o brincar mais livre, tendo também nesse momento um contato com a natureza. Para Surdi, Melo e Kunz (2016), o brincar é subjetivo e permite à criança o conhecimento de seu próprio mundo, sem interferência de ninguém, possibilitando assim que ela se doe por completo nessa atividade.

A professora da turma da pré-escola (entrevista, 17/03/2020) destaca que, mesmo não chamando esse momento de "Educaçáo Física" dentro da aula, "acabo contemplando todo dia atividades [da Educação Física] para que eles [crianças] contemplem novas habilidades”. Ela diz que as atividades relacionadas à Educação Física que realiza com seus educandos geralmente estão articuladas com o tema central da aula. Esse grande espaço da Educaçáo Física no cotidiano da Educação Infantil que a professora destaca se dá, de acordo com ela, "[...] pois trabalha toda essa questáo corporal, de regras, de convivência [...]". Além disso, a educadora acredita que a experiência docente faz com que, automaticamente, ao pensar uma temática de aula, seja vinculada a ela uma prática corporal relacionada à Educação Física.

Diante desse cenário da Educação Física no contexto investigado, observa-se que as três entrevistadas destacam a importância do componente curricular dentro da escola e, sobretudo, na Educaçáo Infantil, apontando alguns conhecimentos que devem ser trabalhados. Contudo, é importante destacar que as ideias das docentes, relacionadas aos conhecimentos com que a Educação Física trabalha, estáo vinculadas a uma ideia tradicional, que privilegiava o domínio de técnicas, gestos, capacidades e habilidades. É preciso entender que o que foi citado por elas é, sim, trabalhado pela Educação Física, mas o componente curricular não se restringe a isso. Assim, além do entendimento das docentes sobre a Educação Física na Educação Infantil, é necessário atentar para o que a BNCC (BRASIL, 2018) diz sobre o ensino da Educação Física para crianças.

Apesar de náo estabelecer conhecimentos a serem trabalhados em cada faixa etária por meio de áreas de conhecimento, para a Educação Infantil, a BNCC (BRASIL, 2018) define "Campos de Experiência", em que são organizados os saberes para cada idade. Assim, não existe um conhecimento somente vinculado à Educação Física. Dessa forma, cada área deve procurar seu espaço dentro desses campos. A Educaçáo Física possui uma relação com todos os campos apresentados pela Base, mas o que mais se relaciona com esse componente curricular é o campo "Corpo, gestos e movimentos". De acordo com o documento, esse segmento prevê o trabalho de conhecimentos relacionados ao desenvolvimento da coordenaçáo motora, manipulação de objetos, exploração do corpo, criatividade, autonomia e conscientização sobre hábitos saudáveis. 
O conhecimento sobre o contexto escolar e o espaço da Educação Física na Educação Infantil do educandário permite pensar possíveis caminhos para efetivar os objetivos de educação abrangendo conhecimentos significativos às crianças. Sendo assim, relacionando a proposta da escola com os objetivos de ensino da Educação Física na Educação Infantil e entendendo as características do meio pesquisado, identificou-se como uma possibilidade o desenvolvimento do ensino por um projeto com a temática jogos e brincadeiras tradicionais, relacionados com o mundo de vida, articulando a Educaçáo Física com a Educação Infantil. Isso será abordado na seção seguinte.

\section{VOANDO AINDA MAIS LONGE: escola e família contribuindo para um projeto de jogos e brincadeiras tradicionais na Educaçáo Infantil}

Para nortear a proposta de projeto sobre jogos e brincadeiras tradicionais, foram admitidos os seguintes eixos estruturantes, que representam características perceptíveis no cotidiano do contexto investigado: diversidade cultural; o trabalho de conhecimentos que perpassam o ambiente da sala de aula e relacionam-se com a vida da criança; a prática constante de brincadeiras e jogos por parte das crianças no ambiente da escola; e a importância do espaço de fala e opiniáo do educando nas aulas.

O brincar pode ser interpretado como um processo criativo vinculado aos fenômenos da curiosidade e da intencionalidade. Santin (2003, p. 108) complementa que "o brincar faz nascer o homem", pois é a partir de seus movimentos, imaginaçóes e criatividade que ele se expressa por meio das brincadeiras já na infância. A partir disso, o movimento humano nas primeiras experiências das crianças passa a ter significado, na medida em que determinadas açôes realizadas possuem intenções.

Nessa perspectiva, entende-se que o brincar proporciona também a construçáo de conhecimentos. Kunz e Costa (2015) colocam o brincar como movimento inerente às crianças, repleto de atos de liberdade, espontaneidade e criatividade. Sendo assim, é evidente a grande dimensão que o brincar representa na formação do indivíduo com relação a aspectos sociais, culturais, corporais e emocionais, contribuindo para os primeiros "voos" e descobertas das crianças.

Essa construção de saberes proporcionada pelo brincar, principalmente na infância, também é percebida nos jogos. Para Neira (2009), o jogo deve ser uma atividade espontânea e automotivada. $\mathrm{O}$ ato de jogar supóe uma herança cultural e, além disso, trabalha diretamente no nosso bem-estar. Jogar, de acordo com o autor, é também uma forma de conhecermos e nos relacionarmos com o mundo a nossa volta. $\mathrm{O}$ autor sustenta que o jogo é um artefato cultural, e isso deve ser considerado em sua utilização, tendo em vista os diferentes contextos educacionais existentes. Dessa forma, "[...] significa que não basta aos alunos conhecer dezenas de jogos" (NEIRA, 2009, p. 37). É preciso ir além do conhecer. A utilizaçáo dos jogos precisa significar para as crianças, estar vinculada ao contexto cultural delas e respeitar a cultura lúdica que a criança traz para o jogo. 
O entendimento sobre as características do brincar e do jogar proporciona a relação com o contexto investigado neste estudo. A docente da turma da pré-escola enfatiza a importância do momento do brincar, dando espaço para tal em todos os dias da semana. Por sua vez, as crianças aplicam práticas vivenciadas e trazem jogos para a escola, como, por exemplo o jogo "pedra, papel, tesoura", utilizando-os na maioria das vezes nos momentos de espera, quando estáo em fila ou no recreio.

A partir disso, entende-se que os jogos e as brincadeiras são potenciais temáticas para se pensar um projeto de ensino nessa realidade escolar. Isso porque o início de um projeto se dá a partir da cultura do contexto. Dessa forma, para desenvolver um projeto e pautar a construção de saberes em torno dele, é de fundamental importância, por parte do professor, o conhecimento sobre o contexto em que leciona, bem como sobre as crianças com as quais convive. $\mathrm{O}$ docente precisa conhecer o que desperta interesse e curiosidade nas crianças, pois são esses os principais fatores motivadores da criação de um projeto (GIROTTO, 2006).

Essa atenção à cultura é importante na Educação Física. De acordo com Neira (2018, p. 8), a partir da mudança do objeto de estudo da Educação Física, de exercício físico e movimento para cultura corporal de movimentos, as práticas corporais configuraram-se "[...] como produtos da gestualidade, formas de expressão e comunicação passíveis de significação, ou seja, artefatos da cultura”. Desse modo, o currículo cultural da Educação Física objetiva a conexão de diferentes manifestações culturais, promovendo o estudo delas através de análises e compartilhamento de seus significados, na medida em que a escola é concebida como um ambiente propício para as discussóes, experiências, ressignificação e ampliação da cultura corporal (NEIRA, 2018).

Com base nisso, entende-se que a cultura está presente em todos os locais, e no espaço educacional acontece um encontro de culturas, na medida em que cada criança faz parte de um contexto social diferente. $\mathrm{O}$ entendimento das crianças sobre a Educação Física para além do movimento e exercício, pensando nas práticas como culturas, é importante para pensar a formação de cidadáos preparados para uma sociedade menos desigual (NEIRA, 2018). Sendo assim, nos deparamos com outro eixo presente no contexto investigado, que se refere ao trabalho de conhecimentos para além dos muros da escola, relacionados, portanto, ao cotidiano da vida das crianças.

Na Pedagogia de Projetos, de acordo com Hernandez e Ventura (1998), os conhecimentos trabalhados tendem a avançar em mais de uma área de conhecimento. É necessário pensar a construção de conhecimento de forma global, ou seja, o conhecimento trabalhado em aula deve fazer sentido para a vida da criança fora da escola. A aprendizagem acontece a partir da construção de "andaimes" e relaçóes com sentido. Aliado a isso, Hernandez (2014, p. 67) diz que o conhecimento pode ser construído "a partir do diálogo, da intuição, do encontro com outros e da experimentação".

Para Freire (1996, p. 98), "a educação é uma forma de intervenção no mundo". A partir disso, podemos entender que os conhecimentos trabalhados na 
escola podem ser estendidos do contexto da sala de aula, ampliados e disseminados quando em sociedade. "Quando o homem compreende sua realidade, pode levantar hipóteses sobre o desafio dessa realidade e procurar soluçóes. Assim, pode transformá-la e com seu trabalho pode criar um mundo próprio [...]" (FREIRE, 2003, p. 16).

Dessa forma, a relação entre as falas de Hernandez e Freire se articula com a prática pedagógica da professora da pré-escola (entrevista, 17/03/2020) quando ela cita que trabalha inicialmente conhecimentos que fazem parte "da rotina dos alunos". Assim, as três falas idealizam a construção de um conhecimento com significado e que perpasse os muros da escola, tornando a criança capaz de disseminar e utilizar o conhecimento adquirido em sala de aula também em outros contextos em que vive.

Outro eixo identificado a partir das entrevistas e observaçáo foi a característica docente de instigar e provocar situaçóes onde se abre espaço para a opinião e fala das crianças, o que é importante ser considerado, uma vez que já está afirmada no contexto e estimula a capacidade crítica dos educandos. Pensando a partir disso, podemos relacionar essa identidade do contexto com a abordagem de Concepçóes Abertas no ensino da Educação Física. Nela a criança deve ser instigada à capacidade do questionamento; agir autonomamente; tomar decisões pessoais e coletivas; e agir de forma comunicativa, cooperativa e criativa (HILDEBRANDT-STRAMANN, 2011).

Essa situação do processo de ensino destacada acima é um aspecto importante na Pedagogia de Projetos. Essa metodologia favorece a formação de um sujeito capaz de dialogar, produzir, questionar, pesquisar e solucionar problemas. Para tanto, o papel docente deve ser diferenciado se comparado a metodologias tradicionais de ensino. É importante para a concretização dos objetivos dessa metodologia que o professor incentive a procura por novas descobertas e saberes por parte das crianças. O papel do professor vai muito além de transmitir conhecimentos, passando a ser oportunizar situaçôes de aprendizagem, assumindo uma mediação entre conhecimento e criança. Dessa forma, a aprendizagem náo pode ser pautada somente no ato de gravar os conhecimentos passados pelo professor, e o ensinar não se refere a passar conteúdos prontos aos alunos (HERNANDEZ; VENTURA, 1998).

Para "bater asas" de forma articulada e síncrona, é importante pensar possibilidades docentes que efetivem o "voo". Nesse sentido, a relação entre proposta de ensino, contexto e metodologia de trabalho abre espaço para uma diversa gama de conhecimentos relacionados à temática de jogos e brincadeiras tradicionais a serem trabalhados nas aulas de Educaçáo Física. As possibilidades neste trabalho destacadas trabalham o envolvimento em conjunto de família e escola para a concretização do "voo" para o conhecimento por parte da criança. Além disso, são propostas atividades relacionadas a jogos e brincadeiras que envolvem o fator cultural, os temas transversais e a interdisciplinaridade.

Aliado ao fato de ser uma temática potencial para o contexto investigado, outro aspecto que favorece a abordagem de jogos e brincadeiras tradicionais nas aulas 
de Educação Física é a diminuição dessas práticas em vários contextos da sociedade, o que pode provocar o esquecimento delas. Neste sentido, uma possibilidade é o trabalho de um resgate histórico e cultural com a participaçáo dos pais dos discentes. As crianças poderiam levar para casa uma entrevista/questôes para seus pais, na qual os responsáveis relatariam os jogos e brincadeiras que costumavam praticar quando eram crianças. A partir disso, as crianças trariam essas informaçóes para a aula e explicariam para a turma sobre as vivências que seus pais contaram, podendo o grupo praticar as atividades mais relatadas.

Além disso, outra possibilidade é trazer a família para dentro do contexto escolar e aproximá-las do projeto, pois é interessante pensar a construção conjunta entre crianças e pais. Dessa forma, poderia ser destinado um dia para que os familiares viessem à escola e brincassem com seus filhos as brincadeiras citadas anteriormente por eles.

Com os pais presentes na escola e contribuindo com ela para fortalecer as "asas" de seus filhos, estes poderiam pintar brincadeiras e jogos no chão do pátio da escola, como "Amarelinha", "Jogo da velha", entre outras. Assim as brincadeiras tradicionais abordadas no projeto alcançariam todos os estudantes do educandário, visto que estariam expostas em um ambiente de convivência.

Uma das metas previstas no Projeto Político Pedagógico (2019, p. 33) é a participaçáo dos pais "de forma comprometida no processo de ensino-aprendizagem e na disciplina, visando à formação integral de seus filhos”. Sendo assim, acredita-se que práticas que estreitam as relações entre escola e família potencializam o interesse familiar com relação às aprendizagens e aos trabalhos desenvolvidos por seus filhos na escola.

É importante salientar o envolvimento da família na realização de um projeto, pois, como já vimos, o conhecimento trabalhado em sala de aula se expande para os outros contextos que a criança frequenta. Hernandez (2014) alia a família aos docentes e discentes como autores do conhecimento pedagógico. Para o autor, os trabalhos desenvolvidos na aula potencializam-se ao adentrarem no contexto familiar. Na perspectiva de Freire (1996), entendemos que é interessante estreitar as relaçóes entre escola e família. Para isso, é importante considerar as condiçôes em que as crianças vivem, bem como seus conhecimentos por meio de suas experiências prévias em outros contextos, dando espaço para suas manifestaçóes em sala de aula.

Trabalhando em conjunto para o "voo", a proposta pedagógica para a turma e o Projeto Político Pedagógico da escola possibilitam também um trabalho relacionado a questóes sobre o meio ambiente, em especial o recolhimento de materiais recicláveis. Assim, outra atividade que poderia ser realizada é a confecçáo de brinquedos para brincadeiras. Esse trabalho também poderia envolver a família das crianças, na medida em que eles necessitariam de auxílio adulto para a produção. Ao trazerem os brinquedos confeccionados em casa para a escola, as crianças seriam instigadas a exercitar o brincar e a compartilhar seus brinquedos, trocando com os colegas. Quando terminadas as experiências em sala de aula, os brinquedos poderiam fazer parte do "Espaço Brincar", que é a brinquedoteca do 
educandário. Assim, o interesse por brinquedos a partir de materiais reciclados poderia atingir outros estudantes da escola.

Quando pensamos em jogos e brincadeiras tradicionais, nos deparamos com um universo muito amplo. Isso porque, ao longo dos anos, muitas práticas foram passadas de geração a geração. Quando olhamos para isso, estamos pensando também em diferentes momentos históricos e culturais. Para Neira (2009), o jogo é uma manifestação cultural, contudo, na maioria das vezes, nas aulas de Educação Física, só é dada atenção ao desenvolvimento cognitivo que o jogo pode promover, deixando-se de lado as discussões potenciais na relaçáo jogo e cultura. Sobre isso, Neira (2009, p. 36) destaca que muitos autores colocam o jogo apenas como estratégia para alcançar objetivos, e "não perceberam que enquanto tema, o jogo é conteúdo e, dessa forma, precisa ser trabalhado com toda a riqueza nele contida quando este se apresenta como cultura".

Com base nisso, é interessante pensar os jogos e brincadeiras estreitamente relacionados ao fator da cultura, uma vez que esse é o foco da Educação Física. Assim, mostrar e praticar com as crianças uma brincadeira ou jogo que é realizado(a) de diversas formas em diferentes partes do país e do mundo pode instigar o interesse e a curiosidade das crianças pelo que é diferente e vai além do seu contexto. Dessa forma, o conhecimento sobre jogos e brincadeiras transcende o espaço da Educação Física. Além disso, interdisciplinarizando o conhecimento com base nos interesses das crianças, é possível avançar em aspectos históricos, geográficos, culturais e sociais, permitindo às crianças estabelecerem relaçóes entre os saberes, indo além do raso e potencializando suas aprendizagens.

O jogo "Pedra, papel, tesoura", que já vem sendo praticado por algumas crianças em momentos de espera no educandário, poderia ser explorado a partir do uso de materiais concretos. Assim, utilizando uma pedra, um papel e uma tesoura, seria possível ensinar as regras do jogo para as crianças que não conhecem, de uma maneira mais visual e dinâmica, tornando mais fácil o aprendizado.

Dentro de um projeto, há de se pensar na criação e produção por parte da criança. Neste sentido, é possível mostrar brincadeiras ou jogos utilizando alguns materiais, como bolas, cordas e bambolês. A partir disso, poderia ser estimulada a criaçáo de novas brincadeiras a partir de ideias das crianças, trabalhando sua criatividade e autonomia, aspectos importantes na Pedagogia de Projetos. Além disso, o olhar para as ideias e sugestóes das crianças contribui para que eles se sintam importantes no processo de ensino (HILDEBRANDT-STRAMANN, 2011). Para Neira (2009, p. 38), "no processo de dar voz às crianças, o professor poderá descobrir a capacidade delas se expressarem através da linguagem lúdica (cantando, dançando, fazendo mímica, jogando) e, também, a linguagem oral, a forma dominante em sua cultura".

Outro exemplo muito interessante pensando em brincadeiras tradicionais é o "Carrinho de mão". Essa é uma brincadeira que pode ser praticada de diferentes maneiras e em diversas situaçóes. Pode ser instigada apenas pelo fato do brincar, porém também pode ser inserida em circuitos. Um aspecto que chama a atenção 
nesta atividade é a cooperação, que se entrelaça com relaçáo aos objetivos de formação do indivíduo por parte da escola, da Educaçáo Física e do ensino por projetos.

As tradicionais brincadeiras de rodas e rodas cantadas são também ótimas possibilidades para o projeto. As crianças geralmente possuem facilidade de aprenderem essas brincadeiras, e elas estimulam questôes como movimento, ritmo e voz. No projeto, a inserção delas poderia partir do conhecimento das crianças. Após, poderiam ser praticadas outras brincadeiras e rodas cantadas.

Com relação às rodas cantadas, as músicas "Se eu fosse um peixinho" e "Ciranda-cirandinha" são bons exemplos. A maior parte das rodas cantadas possui uma música que também conta uma história. Partindo disso, os discentes poderiam ser instigados a criarem ilustraçóes sobre a história cantada. No trabalho posterior à experiência com "Ciranda-cirandinha", a partir da parte que diz "diga um verso bem bonito", as crianças poderiam pesquisar versos com os pais e trazerem para a aula. Ainda poderiam realizar a roda em casa com sua família e, a partir de palavras centrais que pertencem à música, criar uma história. No caso de "Se eu fosse um peixinho", as crianças poderiam estudar o animal peixe e identificar características relacionadas a ele. Os materiais produzidos pelas crianças, tanto na escola quanto em casa, podem ser expostos no educandário.

Já na cantiga "Terezinha de Jesus", é possível identificar uma cena acontecendo. Essa história que acontece na cantiga poderia ser contada inicialmente para as crianças, e, após, ser realizada a prática em roda. É uma cantiga que pode potencializar as expressóes das crianças e também o contato com os outros, já que acaba quando uma criança escolhe outra para abraçar. A análise de conteúdo das cançôes possibilita as crianças compreenderem o que estáo cantando e, a partir disso, entenderem a música, facilitando o desenvolvimento, por exemplo, das expressóes.

As famosas brincadeiras de roda como "Dança das cadeiras" e "O limão entrou na roda" também potencializam questóes que vão além da Educação Física. As duas brincadeiras citadas envolvem a concentração. A "Dança das cadeiras" é uma brincadeira que possui muitas variações. Uma variação possível é torná-la cooperativa, na medida em que vão se retirando cadeiras e todos as crianças devem sentar, mesmo que apoiados em outros colegas ou dividindo uma mesma cadeira. No caso de "O limão entrou na roda", também são possíveis variações. É possível realizar essa brincadeira em diversas velocidades, fazendo com que se exija agilidade por parte das crianças. A organização delas no espaço pode ser alterada do habitual nessa brincadeira. Ela pode ser organizada em outras formas geométricas que não $o$ círculo. Assim, adentra para outros conhecimentos, de outras áreas. Além disso, o conhecimento das frutas, potencializado pelo conhecimento inicial sobre o limão, também pode ser promovido.

De acordo com o Projeto Político Pedagógico (2019), o Grêmio Estudantil da escola é responsável uma vez por semana pela realização do "Recreio Legal". Esse projeto visa a direcionar atividades para os estudantes da Educação Infantil e dos Anos Iniciais no momento do recreio. Para Neuenfeldt (2005), o momento 
do recreio náo pode ficar oculto dentro da escola e deve ser pensado e refletido. Segundo o autor, o recreio é um espaço para o movimento e o brincar, no qual acontecem muitas trocas entre os estudantes da escola. Assim, é possível que o projeto de jogos e brincadeiras tradicionais adentre esse espaço. Pode ser criado mais um espaço na semana do educandário, no qual haja um recreio com atividades dirigidas e relacionadas à temática trabalhada.

A partir disso, é possível perceber a grande dimensão que os jogos e brincadeiras representam, tanto para a infância quanto para a Educação Física. Entende-se que por trás de um jogo ou uma brincadeira existe, sim, uma intençáo e um objetivo, mas, além disso, existe um conhecimento que estamos manipulando. Esse conhecimento refere-se à dimensão cultural, que, quando admitida pelo docente, pode avançar em discussóes relacionadas "aos papéis de gênero, classe e etnia, podendo, mediante a reflexão e o diálogo, desmistificá-los" (NEIRA, 2009, p. 37). Assim, compreende-se que os conhecimentos trabalhados e as provocaçóes estimuladas a partir da temática jogos e brincadeiras tradicionais contribuem para um resgate cultural, bem como tendem a avançar para outras dimensôes além da Educação Física e até mesmo da escola, ampliando os horizontes para futuros "voos" das crianças.

\section{CONCLUÍMOS O VOO?}

Este estudo evidenciou a potencialidade do Ensino por Projetos na Educação Infantil, como abordagem de ensino capaz de articular a proposta do educandário com a Educação Física escolar. É possível identificar uma relação entre os ideais de Freire (1996), das abordagens críticas da Educação Física (HILDEBRANDTSTRAMANN; LAGING, 2011) e da Pedagogia de Projetos (HERNANDEZ; VENTURA, 1998), permitindo um trabalho articulado para "alçar o voo" na docência com crianças.

A criança deve ser compreendida considerando o que ela é e não como um adulto em miniatura. A Educação Infantil contribui para os primeiros avanços relacionados ao seu desenvolvimento e formaçáo, bem como configura-se como um espaço das primeiras socializaçóes. Dessa forma, é necessário um pensar atento sobre a docência nessa etapa da educação, objetivando a oferta de situaçóes pedagógicas que promovam a ludicidade, a imaginação, a criação e a recriaçáo.

A Educação Física é um componente curricular obrigatório na Educação Infantil, e sua presença nessa etapa da Educação Básica é de fundamental importância a partir do conhecimento dos objetivos da BNCC (BRASIL, 2018). Assim, é necessário haver intenções pedagógicas pensando na formação integral das crianças, partindo da oferta de diversas oportunidades e experiências a elas.

No contexto investigado, não há professor específico de Educação Física e nem um momento certo destinado para esse componente escolar na Educação Infantil. A partir disso, percebe-se um esforço da docente da turma da pré-escola em construir aprendizagens referentes à Educação Física com as crianças, seja por meio 
do brincar ou por situaçóes de práticas corporais que também estejam relacionadas com o tema central das aulas.

Vale destacar a importância de conhecer a realidade das crianças e do contexto em que se leciona para o planejamento e ação docente. Isso porque é fundamental que os conhecimentos abordados em aula façam sentindo às crianças, podendo elas mesmas construírem uma relaçáo entre conhecimento e o mundo que as cerca. Além disso, a construção de saberes se potencializa quando pensada a partir de interesses e necessidades dos educandos, haja vista que possui relaçáo direta com seus cotidianos. Foi possível identificar que no contexto investigado há uma preocupação na participação da formação do estudante não somente para a escola, mas também para a vida.

Os resultados deste estudo partem dessa compreensão sobre a realidade e o mundo de vida das crianças. Esse fator foi fundamental para estabelecer eixos centrais em que o projeto poderia se basear para fazer sentido ao contexto. A participação e o envolvimento da família, como uma "asa" aliada à escola para o "voo" das crianças, é uma filosofia do educandário, e por isso foi importante nas articulaçóes promovidas para pensar o projeto de Educação Física na turma investigada. A partir disso, foi possível identificar possíveis práticas do projeto que estão relacionadas não só com conhecimentos específicos da Educação Física, mas também com fatores culturais, de temas transversais e que possibilitam a interdisciplinaridade. Isso se deu porque o tema jogos e brincadeiras tradicionais possibilita articulação com diversas áreas do conhecimento e, sendo assim, entende-se que quanto mais diversificado e abrangente for o projeto, mais eficiente e forte será o "bater das asas" para experiências e conhecimentos.

Destaca-se a importância de pensar a docência intencionando uma formação crítica por parte das crianças. Na Educação Física da Educação Infantil, é necessária uma prática pedagógica centrada na criança, desenvolvendo sua autonomia, criatividade e cooperação. É interessante trabalhar com situaçóes de ensino que dão oportunidade de fala às crianças, desenvolvendo sua capacidade de expressão e oralidade. É possível fazer relaçôes entre elementos específicos da Educação Física com uma infinidade de aspectos relacionados a outras áreas de conhecimento, favorecendo um trabalho interdisciplinar e impulsionando conhecimentos para além dos muros da escola. Para isso, há a necessidade de mais estudos da Educação Física no que tange a etapa de Educação Básica da Educação Infantil, tendo em vista que esse componente curricular é muito importante para as crianças.

Por fim, entende-se que o "voo" da educaçáo é infinito e por isso nunca será concluído. Como próximo passo desta investigação, a realização de uma pesquisaação é uma possibilidade potencial. Essa prática oportunizará compreensões reais sobre aprendizagens desse "bater de asas" em conjunto que o projeto pode promover no "voo" para o conhecimento da criança, expandindo seus horizontes a partir da saída de seu ninho. 


\section{REFERÊNCIAS}

ARIÈS, Phillippe. História Social da Criança e da Família. Rio de Janeiro: LTC, 2012.

AYOUB, Eliana. Reflexões sobre a Educação Física na Educação Infantil. Revista Paulista de Educaçáo Física, São Paulo, supl. 4, p. 53-60, 2001. Disponível em: <http://www. revistas.usp.br/rpef/article/view/139594>. Acesso em: 28 mai. 2019.

BASEI, Andréia P. A Educação Física na Educação Infantil: a importância do movimentar-se e suas contribuiçôes no desenvolvimento da criança. Revista Iberoamericana de Educación, n. 47/3, 2008. Disponível em: <https://rieoei.org/ historico/deloslectores/2563Basei.pdf >. Acesso em: 03 jun. 2020.

BRASIL. Base Nacional Comum Curricular (BNCC). Educação é a Base. Brasília, 2018. Disponível em: <http://basenacionalcomum.mec.gov.br/images/BNCC_EI_ EF_110518_versaofinal_site.pdf>. Acesso em: 14 abr. 2019.

FONSECA, João José Saraiva da. Metodologia da Pesquisa Científica. Curso de Especialização em Comunidades Virtuais de Aprendizagem - Informática Educativa. Maio de 2002. Universidade Estadual do Ceará. Disponível em: <http://www.ia.ufrrj.br/ ppgea/conteudo/conteudo-2012-1/1SF/Sandra/apostilaMetodologia.pdf >. Acesso em: 21 mai. 2019.

FREIRE, João Batista. Educaçáo de Corpo Inteiro: teoria e prática da Educação Física. São Paulo: Scipione, 1994.

FREIRE, Paulo. Pedagogia da Autonomia: saberes necessários à prática educativa. São Paulo: Paz e Terra, 1996. Coleção leitura.

Educaçáo e Mudança. Rio de Janeiro: Paz e Terra, 2003. v. 27.

GIROTTO, Cyntia Graziella Guizelim Simóes. A metodologia de projetos e a articulaçáo do trabalho didático-pedagógico com as crianças pequenas. Educaçáo em Revista, Marília, v. 7, n. 1/2, p. 31-42, 2006. Disponível em: <revistas.marilia.unesp.br/index.php/ educacaoemrevista/article/view/605/488>. Acesso em: 18 mai. 2019.

HERNÁNDEZ, Fernando. Entrevista com o professor Fernando Hernández. [Entrevista concedida a] Anamaria Kurtz de Souza Welp, Simone Sarmento e William Kirsch. Revista Bem Legal, Porto Alegre, v. 4, n. 1, p.65-72, 2014. Disponível em: <http://www.ufrgs.br/ revistabemlegal/edicoes-anteriores/no_1_2014/entrevista>. Acesso em: 15 mai. 2020.

HERNÁNDEZ, Fernando; VENTURA, Montserrat. A organizaçáo do currículo por Projetos de Trabalho: o conhecimento é um caleidoscópio. Porto Alegre: Artmed, 1998. v. 5.

HILDEBRANDT-STRAMANN, Reiner. A formação de professores de Educação Física para escolas públicas na Alemanha. Revista da Educaçáo Física/UEM, Maringá, v. 14, n. 2, p. 97-103, 2003. Disponível em: <http://eduemojs.uem.br/ojs/index.php/RevEducFis/ article/viewFile/3475/2489>. Acesso em: 15 mai. 2020. 
2009.

. Educaçáo Física aberta à experiência. Rio de Janeiro: Imperial Novo Milênio,

HILDEBRANDT-STRAMANN, Reiner; LAGING, Ralf. Concepçóes abertas no ensino da Educaçáo Física. Rio de Janeiro: Imperial Novo Milênio, 2011. 160 p.

HORN, Cláudia Inês. Documentação Pedagógica: a produção da criança protagonista e do professor designer. (Tese) Doutorado em Educação. Programa de Pós-Graduação, Universidade do Vale do Rio dos Sinos. Sáo Leopoldo, p. 267. 2017.

KUNZ, Elenor. Educação Física: ensino e mudança. Ijuí: Ed. Unijuí, 1991.

KUNZ, Elenor; COSTA, Andrize Ramires. A imprescindível e vital necessidade da criança: "Brincar e Se-Movimentar". In: KUNZ, Elenor (org.). Brincar \& SeMovimentar: tempo e espaços de vida da criança. Ijuí: Unijuí, 2015. p. 13-37.

MINAYO, Maria Cecília de Souza (org.). Pesquisa Social: Teoria, método e criatividade. 21 ed. Petrópolis: Vozes, 2002. Disponível em: <https://wp.ufpel.edu.br/franciscovargas/ files/2012/11/pesquisa-social.pdf>. Acesso em: 21 mai. 2019.

MORAES, Roque. Mergulhos discursivos: análise textual qualitativa entendida como processo integrado de aprender, comunicar e interferir em discursos. In: GALIAZZI, Maria do Carmo; FREITAS, José Vicente. Metodologias emergentes de pesquisa em Educação Ambiental. Ijuí: Unijuí, 2007, p. 85-114.

MOURA, Tiago Bastos de; VIANA, Flávio Torrecilas; LOYOLA, Viviane Dias. Uma Análise de Concepçóes Sobre a Criança e a Inserção da Infância no Consumismo.

Psicologia: Ciência e Profissão, Brasília, v. 33, p. 474-489, 2013. Disponível em: <https://www.scielo.br/pdf/pcp/v33n2/v33n2a16.pdf>. Acesso em: 08 abr. 2020.

NEGRINE, Airton. A pesquisa qualitativa na educação física: alternativas metodológicas. Porto Alegre: Sulina, 2010. v.3.

NEIRA, Marcos Garcia. Em defesa do jogo como conteúdo cultural do currículo da Educação Física. Revista Mackenzie de Educaçáo Física e Esporte, São Paulo, v. 8, p. 25-41, 2009. Disponível em: <http://editorarevistas.mackenzie.br/index.php/remef/ article/view/1719>. Acesso em: 20 mai. 2020.

. O currículo cultural da Educação Física: Pressupostos, princípios e orientaçóes didáticas. Revista e-Curriculum, São Paulo, v. 16, n. 1, p. 4-29, 2018. Disponível em: $<$ https://revistas.pucsp.br/index.php/curriculum/article/view/27374>. Acesso em: 20 mai. 2020.

NEUENFELDT, Derli Juliano. Recreio escolar: espaço para "recrear" ou necessidade de “recriar” este espaço? Lajeado: UNIVATES, 2005.

Educação ambiental e Educação Física escolar: uma proposta de formação de professores a partir de vivências com a natureza. Tese (Doutorado em Ambiente e 
Desenvolvimento) - Programa de Pós-Graduação Stricto Sensu, Universidade do Vale do Taquari. Lajeado, p. 234. 2016.

NIEHUES, Mariane Rocha; COSTA, Marli de Oliveira. Concepçóes de Infância ao longo da história. Revista Técnico Científica (IFSC), Florianópolis, v. 3, n. 1, p.284-289, 2012. Disponível em: <http://periodicos.ifsc.edu.br/index.php/rtc/article/viewFile/420/342>. Acesso em: 15 abr. 2019.

OLIVEIRA, Amauri Aparecido Bassoli de. Metodologias emergentes no ensino da Educação Física. Revista da Educaçáo Física/UEM, Maringá, v. 8, n. 1, p. 21-27, 1997. Disponível em: <https://www.researchgate.net/publication/277201034_ METODOLOGIAS_EMERGENTES_NO_ENSINO_DA_EDUCACAO_FISICA>. Acesso em: 01 mai. 2019.

OLIVEIRA, Nara Rejane Cruz de. Concepção de Infância na Educação Física brasileira: primeiras aproximaçóes. Revista Brasileira de Ciências do Esporte, Campinas, v. 26, n. 3, p. 95-109, 2005. Disponível em: <http://rbce.cbce.org.br/index.php/RBCE/article/ viewFile/162/171>. Acesso em: 30 abr. 2020.

OSTETTO, Luciana Esmeralda. Planejamento na educação infantil mais que a atividade, a criança em foco. In: OSTETTO, Luciana Esmeralda (Org.). Encontros e encantamentos na educaçáo infantil: partilhando experiências de estágios. Campinas: Papirus, 2000.

PERRENOUD, Philippe. Formar professores em contextos sociais em mudança: prática reflexiva e participação crítica. Revista Brasileira de Educaçáo, online, n. 12, 1999. Disponível em: $<$ http://www.anped.org.br/sites/default/files/rbe/files/rbe_12.pdf $>$. Acesso em: 15 mai. 2020.

POCHMANN, Bruna Girelli.; NEUENFELDT, Derli Juliano. Educação Física na Educação Infantil: discutindo a formação inicial e o interesse de atuação de acadêmicos de Educação Física/Licenciatura neste nível de ensino. Cinergis, Santa Cruz do Sul, v. 16, n. 1, p. 20-26, 2015. Disponível em: <https://online.unisc.br/seer/index.php/cinergis/ article/view/5594/4191>. Acesso em: 15 jun. 2020.

PROJETO POLÍTICO PEDAGÓGICO. Escola Municipal de Ensino Fundamental Professora Odila Rosa Scherer. Venâncio Aires. 2019.

QUINTEIRO, Jucirema. O direito à Infância na Escola: por uma Educação contra a Barbárie. Zero-a-Seis, Florianópolis, v. 13, n. 24, 2011. Disponível em: < https:// periodicos.ufsc.br/index.php/zeroseis/article/view/1980-4512.2011n24p22/18110 >. Acesso em: 4 jun. 2020.

SANTIN, Silvino (org.). Educaçáo Física: uma abordagem filosófica da corporeidade. Editora Unijuí: Ijuí, 2003.

SANTOS, Michele B. dos; ROYER, Marcia R.; DEMIZU, Fabiana S. B. Metodologia de ensino por projetos: levando a prática para o ensino de ciências. In: Congresso Nacional 
de Educação, 13, 2017, Curitiba. Anais do XIII Congresso Nacional de Educaçáo. Disponível em: <https://educere.bruc.com.br/arquivo/pdf2017/23884_11929.pdf >. Acesso em: 01 mai. 2019.

STAVISKI, Gilmar; SURDI, Aguinaldo; KUNZ, Elenor. Sem tempo de ser criança: a pressa no contexto da educação de crianças e implicaçôes nas aulas de Educação Física. Revista Brasileira de Ciências do Esporte, Florianópolis, v. 35, n. 1, p. 113-128, 2013. Disponível em: <http://www.scielo.br/pdf/rbce/v35n1/a10v35n1>. Acesso em: 10 abr. 2019.

SURDI, Aguinaldo Cesar; MELO, Jose Pereira de; KUNZ, Elenor. O Brincar e o Se-movimentar nas aulas de Educação Física Infantil: realidades e possibilidades.

Movimento, Porto Alegre, v. 22, n. 2, p. 459-470, 2016. Disponível em: <https://seer. ufrgs.br/Movimento/article/view/58076>. Acesso em: 10 mai. 2020. 